\title{
Correlating Off-Axis Tension Tests to Shear Modulus of Wood-Based Panels
}

\author{
By Edmond P. Saliklis ${ }^{1}$ and Robert H. Falk ${ }^{2}$
}

\begin{abstract}
The weakness of existing relationships correlating off-axis modulus of elasticity $E_{\theta}$ to shear modulus $G_{12}$ for wood composite panels is demonstrated through presentation of extensive experimental data. A new relationship is proposed that performs better than existing equations found in the literature. This relationship can be manipulated to calculate the shear modulus $G_{12}$ of orthotropic specimens such as wood-based panels solely from off-axis tension (or compression) tests. The proposed relationship reduces to classical theory for the isotropic case. In all cases tested, the newly proposed relationship is a better fit to the data than the traditional orthotropic elasticity equation.
\end{abstract}

\section{INTRODUCTION}

The shear strength and modulus of rigidity of composite wood materials are required for the rigorous design of many lumber-panel structural components such as trusses with gusset plates, box beams, folded plate roofs, roof or floor diaphragms, shear walls, and engineered wood products such as the webs of I-joists. Allowable shear strength values are readily available for the design of solid lumber and other engineered wood products such as glulam; however, the elastic shear modulus, or modulus of rigidity $G_{12}$, is often experimentally obtained for new and unique panel products. Yet, it is difficult to readily conduct pure shear tests that could directly calculate $G_{12}$.

Wood composite panel products, similar to those mentioned above, are traditionally modeled as orthotropic solids. In $x-y$ space, the modulus of elasticity (MOE) may vary from its strongest value $E_{1}$ ( $x$-axis aligned with the longitudinal grain direction) to $E_{2}$, typically $90^{\circ}$ away from the strong axis. The problems of complicated test setups and specimen size effects (Annual 1997) notwithstanding, the experimentally obtained shear modulus $G_{12}$ should relate to the two principal MOE $E_{1}$ and $E_{2}$, the Poisson ratio $\nu_{12}$, and to the MOE at some angle $\theta$ to the $x$-axis $E_{\theta}$ by means of coordinate transformation of orthotropic elasticity relations (Jones 1975)

$$
\frac{1}{E_{\theta}}=\frac{\cos ^{4} \theta}{E_{1}}+\frac{\sin ^{4} \theta}{E_{2}}-\frac{2 \nu_{12} \cos ^{2} \theta \sin ^{2} \theta}{E_{1}}+\frac{\cos ^{2} \theta \sin ^{2} \theta}{G_{12}}
$$

Such a relationship is more effective than the empirically derived Hankinson formula (Bodig and Jayne 1982)

$$
E_{\theta}=\frac{E_{1} E_{2}}{E_{1} \sin ^{2} \theta+E_{2} \cos ^{2} \theta}
$$

in capturing the properties of panel products such as plywood, which can have a very small $\mathrm{MOE}$ at $\theta=45^{\circ}$, and large, approximately equal MOE at $\theta=0^{\circ}\left(E_{1}\right)$ and $\theta=90^{\circ}\left(E_{2}\right)$.

The original intention of this study was to investigate the use of (1) as a predictor of the shear modulus solely using uniaxial tests. These uniaxial tests establish $E_{1}, E_{2}$, and $E_{\theta}$. Advantages of measurement of shear modulus by tension tests have been investigated by others (Rosen 1972; Ebrahimi and

\footnotetext{
${ }^{1}$ Asst. Prof., Dept. of Civ. and Envir. Engrg., 315 Alumni Hall of Engineering, Lafayette Coll., Easton, PA 18042-1775.

${ }^{2}$ Res. Engr., U.S. Forest Products Lab., One Gifford Pinchot Dr., Madison, WI 53705-2398.
}

Sliker 1981). A minor difficulty of using (1) to do this, was the need to experimentally obtain Poisson ratios. The proposed method has eliminated this need.

The major difficulty in achieving the original objective was the somewhat surprising realization that (1) is ineffective in modeling $E_{\theta}$. This study has analyzed a historical set of data (Norris and McKinnon 1956) as well as newly gathered data on a variety of wood-based panel products (plywood, oriented strand board, particleboard), and has demonstrated that there is a lack of fit between (1) [or its alternate forms via (3) or (5)] and the experimental data. Standard methods were used to determine $E$ (ASTM D 3500) from $0^{\circ}$ to $90^{\circ}$, and also to determine $G_{12}$ by means of a plate twisting test (ASTM D 3044).

Several researchers have investigated the off-axis MOE by means of traditional theory of elasticity, but without the empirical approach adopted herein. Bindzi and Samson (1995) recently have shown another format of (1) as follows:

$$
E_{\theta}=\frac{E_{1} E_{2}}{E_{1} \sin ^{2} \theta\left(\sin ^{2} \theta+a \cos ^{2} \theta\right)+E_{2} \cos ^{4} \theta}
$$

where the nondimensional parameter $a$ is given by

$$
a=\frac{E_{2}}{G_{12}}-2 \nu_{12}
$$

To complete the review of the literature, another equivalent formulation of (1) was presented by Liu and Ross (1998)

$$
E_{\theta}=\frac{E_{1} E_{2}}{E_{2} \cos ^{2} \theta\left(\cos ^{2} \theta+a \sin ^{2} \theta\right)+E_{1} \sin ^{4} \theta}
$$

where the nondimensional parameter $a$ is given by

$$
a=\frac{E_{1}}{G_{12}}-2 v_{12}
$$

It can be shown, however, that (3) and (5) are completely equivalent to (1) and are, consequently, equally ineffective in modeling composite wood panel MOE variations.

Given the poor performance of (1), the revised objective of this study became the demonstration of an improved equation relating $E_{1} E_{2}, G_{12}$, and $E_{\theta}$. We have proposed such a relationship for modeling $E_{\theta}$, which reduces to the classical elasticity equation for the isotropic case $\left(E_{1}=E_{2}\right)$. This equation can be used in two ways. First, it can be used in conjunction with an experimentally determined $E_{1}, E_{2}$, and $G_{12}$ to better predict $E_{\theta}$. Second, it can be rewritten to solve for $G_{12}$ based on $E_{1}, E_{2}$, and $E_{\theta}$ at any angle $\theta$, each of which could be obtained from tension tests. Using the new relationship to extract $G_{12}$ could be advantageous if the plate twisting test (ASTM D 3044) is not available. 


\section{NEW RELATIONSHIP}

The proposed relationship was formulated to appear similar to (1), yet without the Poisson ratio term. The Poisson ratio term was not included in this relationship to reduce the number of input variables. This simplification is reasonable as the Poisson ratio term in (1) can be one order of magnitude smaller than the others, because $\nu_{12}$ is often approximately 0.1 . Furthermore, this simplification eliminates the need to obtain transverse strains.

Then, the equation was modified to enforce agreement to experimentally obtained shear data by means of curve fitting. This was done by means of the calibrating term containing the nondimensional parameter $A$, where $A=E_{2} / E_{1}$. The result is as follows:

$$
\frac{1}{E_{\theta}}=\frac{\cos ^{4} \theta}{E_{1}}+\frac{\sin ^{4} \theta}{E_{2}}+\frac{\cos ^{2} \theta \sin ^{2} \theta}{\left(A^{2 A}\right) G_{12}}
$$

We have calibrated (7) to the ASTM D 3044 plate twisting data because that standard is based on well-accepted theoretical foundations (Hearmon and Adams 1952; Kuipers 1974). This empirical approach ensured that (7) could also be used to extract the shear modulus solely from tension test data. Having such a broad database to work with gave us confidence in our empirical approach. We have demonstrated that (7) performs better than (1) for a wide variety of wood-based panels.

The second application of (7) is to use it to solve for $G_{12}$ based solely on $E_{\theta}$ tests. Rewriting (7) gives the following results:

$$
G_{12}=\frac{\cos ^{2} \theta \sin ^{2} \theta}{\left(A^{2 A}\right) \cdot\left[\frac{1}{E_{\theta}}-\left(\frac{\cos ^{4} \theta}{E_{1}}+\frac{\sin ^{4} \theta}{E_{2}}\right)\right]}
$$

However, if there is substantial variation in the experimental readings of $E_{\theta}$, then the resulting value calculation of $G_{12}$ may have an unacceptably large variation (Seo et al. 1992). Actually, (8) is unstable at two particular angles, which are a function of the orthotropicity of the material. To minimize the effects of the variation of $E_{\theta}$ in a systematic fashion, we have adopted the method proposed by Seo et al. (1992), who used this method to extract the shear modulus of orthotropic sheets of paper. Therefore

$$
\begin{array}{r}
S=\frac{1}{G_{12}}, \quad(X 1)_{i}=\frac{\cos ^{2} \theta_{i} \sin ^{2} \theta_{i}}{A^{2 A}}, \\
(X 2)_{i}=\frac{\cos ^{4} \theta_{i}}{E_{1}}+\frac{\sin ^{4} \theta_{i}}{E_{2}}-\frac{1}{\left(E_{\theta}\right)_{i}}
\end{array}
$$

where $i=1,2,3, \ldots, n$ number of tests; and all other terms as previously defined. Define

$$
F\left(X 1_{i}, X 2_{i}\right)=\sum_{i=1}^{n}\left(X 1_{i}+X 2_{i}\right)^{2}
$$

Minimizing for $n$ trials

$$
\frac{\partial F}{\partial S}=0
$$

yields

$$
2 \sum X 1_{i}\left(S X 1_{i}+X 2_{i}\right)=0
$$

Then

$$
G_{x y}=\frac{1}{S}=\frac{-\sum\left(X 1_{i}\right)^{2}}{\sum\left(X 1_{i} X 2_{i}\right)}
$$

\section{APPLICATION TO EXPERIMENTAL DATA}

We conducted tests to determine $E_{\theta}$ and $G_{12}$ for plywood, oriented strand board, and particleboard. The value of $E_{\theta}$ was found for $\theta=0^{\circ}, 30^{\circ}, 45^{\circ}, 60^{\circ}$, and $90^{\circ}$ by means of tension tests conforming to ASTM D 3500. Four grades of plywood, three grades of oriented strand board, and four grades of particleboard were tested. Three replicates of these five angles (15 specimens) were tested for each of the 15 different panels for a total of 225 tension tests. Then, 60 plate twisting tests (4 on each panel) were performed on specimens taken from these panels in accordance with ASTM D 3044 to calculate the shear modulus $G_{12}$. These values will be referred to as $G_{123044}$. Table 1 summarizes the materials tested. Also examined were historical data (Norris and McKinnon 1956) on specially fabricated plywood panels. This data set contained 12 replicates of $E_{\theta}$ tests at angles of $\theta=0^{\circ}, 15^{\circ}, 30^{\circ}, 45^{\circ}, 60^{\circ}$, $75^{\circ}$, and $90^{\circ}$, resulting in 84 tension tests for each type of plywood. In all, there were 504 tension tests and 72 shear tests performed on these six types of specially fabricated plywood. Table 2 summarizes the historical data that we analyzed. Table 3 shows an example calculation of how we extracted the shear modulus solely from tension tests. The reason for presenting these calculations is to clarify the steps needed to extract the shear modulus from (8) by means of (9)-(13) and to show that it can easily be performed in a spreadsheet environment. Eqs. (1), (3), (5), and (7) were tested on all of these data in the following manner:

1. First the behavior of all four $E_{\theta}$ equations [(1), (3), (5), and (7)] was checked by putting $E_{1}\left(E_{0^{\circ}}\right), E_{2}\left(E_{90^{\circ}}\right)$, and $G_{123044}$. Graphical representations of typical experimental data (solid symbols); (1), (3), and (5) (solid lines all coinciding); and (7) (dashed line with crosses) are shown in Figs. 1 and 2. Note that the agreement is the best for the newly proposed equation [(7)]. Also note that (1), (3), and (5) all require a value of Poisson's ratio. The following relationship for Poisson's ratio was used (Norris and McKinnon 1956):

$$
v_{12}=\left[\frac{E_{1}}{E_{2}}+1\right] \frac{v_{T L}}{1.036}
$$

TABLE 1. Materials Tested in This Study

\begin{tabular}{l|l|c|c|c|c}
\hline \hline $\begin{array}{c}\text { Panel type } \\
(1)\end{array}$ & $\begin{array}{c}\text { Grade } \\
(2)\end{array}$ & $\begin{array}{c}\text { Thickness } \\
(\mathrm{mm}) \\
(3)\end{array}$ & $\begin{array}{c}\text { Specimen } \\
\text { names } \\
(4)\end{array}$ & $\begin{array}{c}\text { Number of } \\
\text { shear } \\
\text { specimens } \\
(5)\end{array}$ & $\begin{array}{c}\text { Number of } \\
\text { tension } \\
\text { specimens } \\
(6)\end{array}$ \\
\hline Plywood & N & 12.7 & N1, N2 & 8 & 30 \\
& A-C & 12.7 & A1, A2 & 8 & 30 \\
A-C & 19.1 & A3, A4 & 8 & 30 \\
Oriented strand board & C-C & 12.7 & C1, C2 & 8 & 30 \\
& Mill 1 & 12.7 & O1 & 4 & 15 \\
& Mill 2 & 12.7 & O2 & 4 & 15 \\
Marticleboard & Mill 3 & 15.7 & O3 & 4 & 15 \\
& Mill 1 & 15.7 & P1 & 4 & 15 \\
& Mill 2 & 25.4 & P2 & 4 & 15 \\
& Mill 3 & 25.4 & P3 & 4 & 15 \\
& Mill 4 & 25.4 & P4 & 4 & 15 \\
\hline \hline
\end{tabular}

TABLE 2. Materials from Norris and McKinnon Report (1956)

\begin{tabular}{c|c|c|c|c|c}
\hline \hline $\begin{array}{c}\text { Panel } \\
\text { type } \\
(1)\end{array}$ & $\begin{array}{c}\text { Number } \\
\text { of plies } \\
(2)\end{array}$ & $\begin{array}{c}\text { Ply } \\
\text { thickness } \\
(\mathrm{mm}) \\
(3)\end{array}$ & $\begin{array}{c}\text { Specimen } \\
\text { names } \\
(4)\end{array}$ & $\begin{array}{c}\text { Number } \\
\text { of shear } \\
\text { specimens } \\
(5)\end{array}$ & $\begin{array}{c}\text { Number of } \\
\text { tension } \\
\text { specimens } \\
(6)\end{array}$ \\
\hline Plywood & 3 & 1.59 & T2 & 12 & 84 \\
& 5 & 1.59 & T3 & 12 & 84 \\
& 7 & 1.59 & T4 & 12 & 84 \\
& 5 & 0.79 & T5 & 12 & 84 \\
& 7 & 0.79 & T6 & 12 & 84 \\
& 9 & 0.79 & T7 & 12 & 84 \\
\hline \hline
\end{tabular}


TABLE 3. Application of $G_{12}$ Extraction to Data, Specimen T2

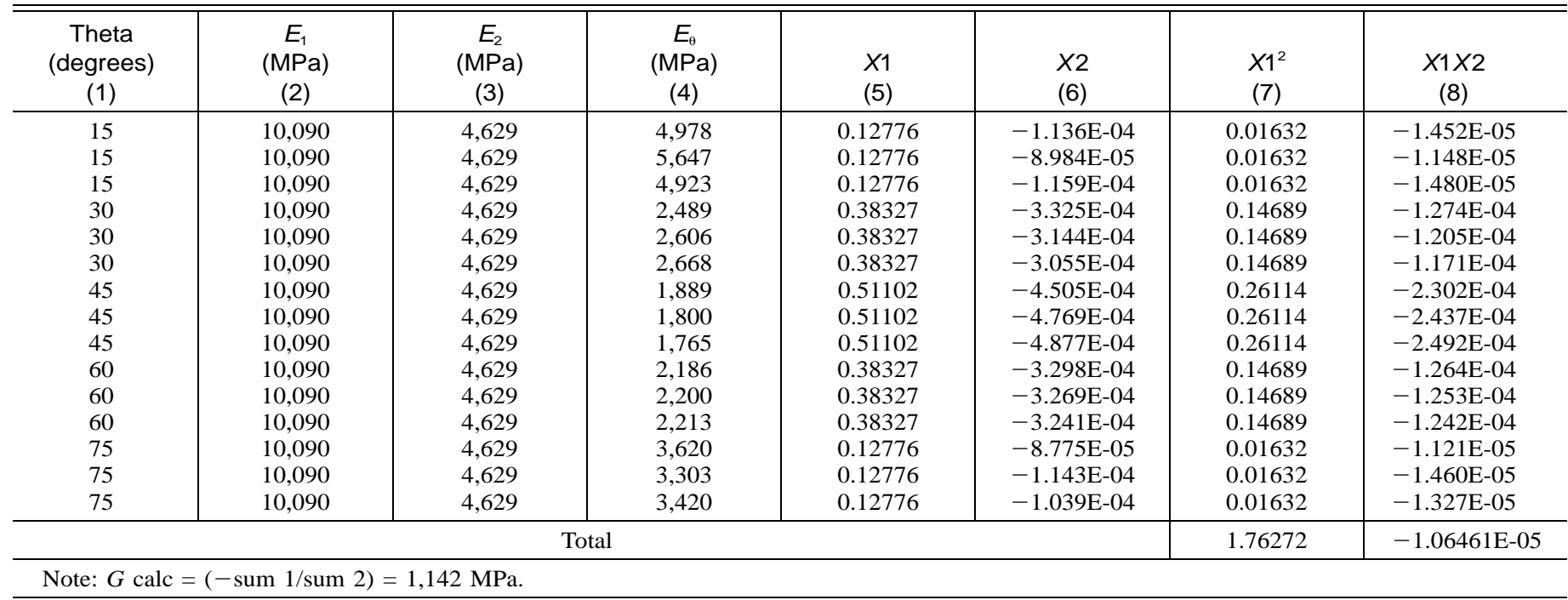

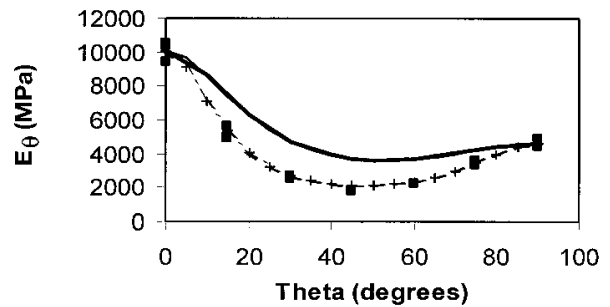

a.) $\mathrm{T} 2 \mathrm{G}_{12 \text { eqn } 7}=1142 \mathrm{MPa} \mathrm{G}_{123044}=1280 \mathrm{MPa}$

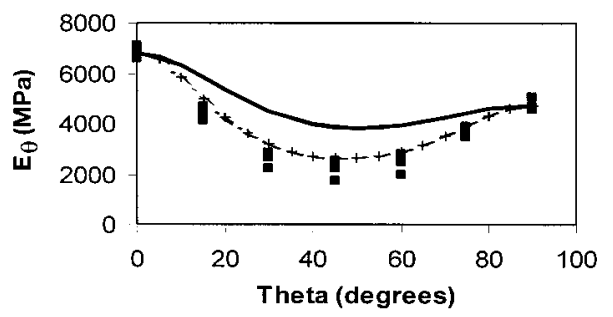

b.) $\mathrm{T} 3 \mathrm{G}_{12 \text { eqn } 7}=1056 \mathrm{MPa} \mathrm{G}_{123044}=1429 \mathrm{MPa}$

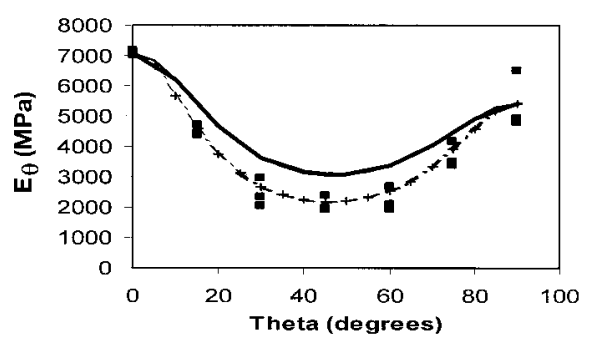

c.) $\mathrm{T} 4 \mathrm{G}_{12 \text { eqn } 7}=886 \mathrm{MPa} \mathrm{G}_{123044}=1005 \mathrm{MPa}$

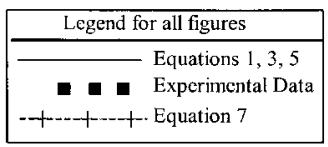

FIG. 1. T2, T3, and T4 Specimens

where $v_{T L}=$ species-dependent material property. For example, for yellow poplar, $\nu_{T L}$ is 0.019 ("The elastic" 1946).

2. The shear modulus calculations, based on the newly proposed (7) as well as the traditional orthotropic elasticity equation [(1)] are compared. In both cases, the error minimization scheme of (9)-(13) was applied. The value of shear modulus extracted from (1) will be designated as

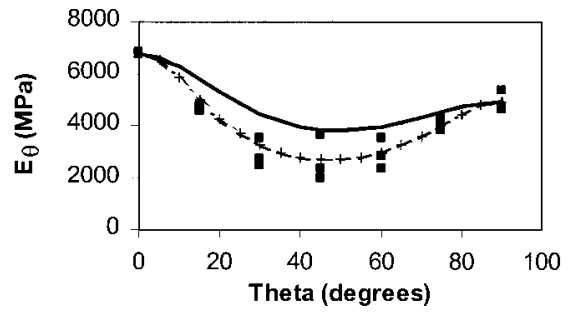

a.) $T 5 \mathrm{G}_{12 \text { eqn } 7}=1257 \mathrm{MPa} \mathrm{G}_{123044}=1409 \mathrm{MPa}$

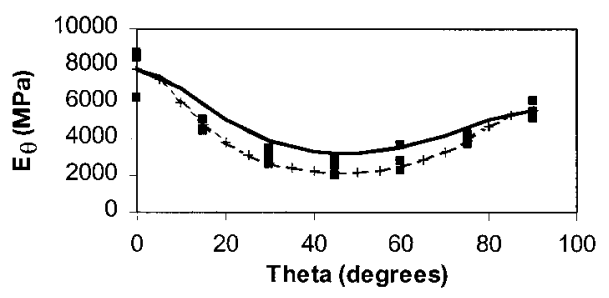

b.) $T 6 \mathrm{G}_{12 \text { eqn } 7}=1211 \mathrm{MPa} \mathrm{G}_{123044}=1056 \mathrm{MPa}$

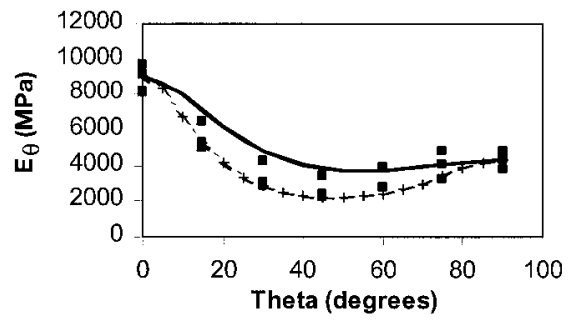

c.) $T 7 \mathrm{G}_{12 \text { eqn } 7}=1758 \mathrm{MPa} \mathrm{G}_{123044}=1382 \mathrm{MPa}$

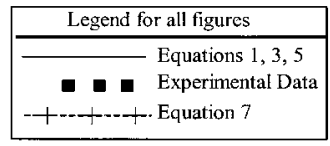

FIG. 2. T5, T6, and T7 Specimens

$G_{12 \text { eqn 1 }}$ and that from (7) will be designated as $G_{12 \text { eqn } 7}$ to differentiate them from the plate twisting test results called $G_{123044}$. Fig. 3 summarizes these findings by showing $G_{123044}$ versus the extracted values of $G_{12 \text { eqn } 1}$ and $G_{12 \text { eqn } 7 .}$. If the extracted values of $G_{12}$ fell on a $45^{\circ}$ line in this plot, then the extracted values would coincide perfectly with the independently obtained plate twisting values $G_{123044}$. Clearly, only $G_{12 \text { eqn } 7}$ falls near the $45^{\circ}$ line. 


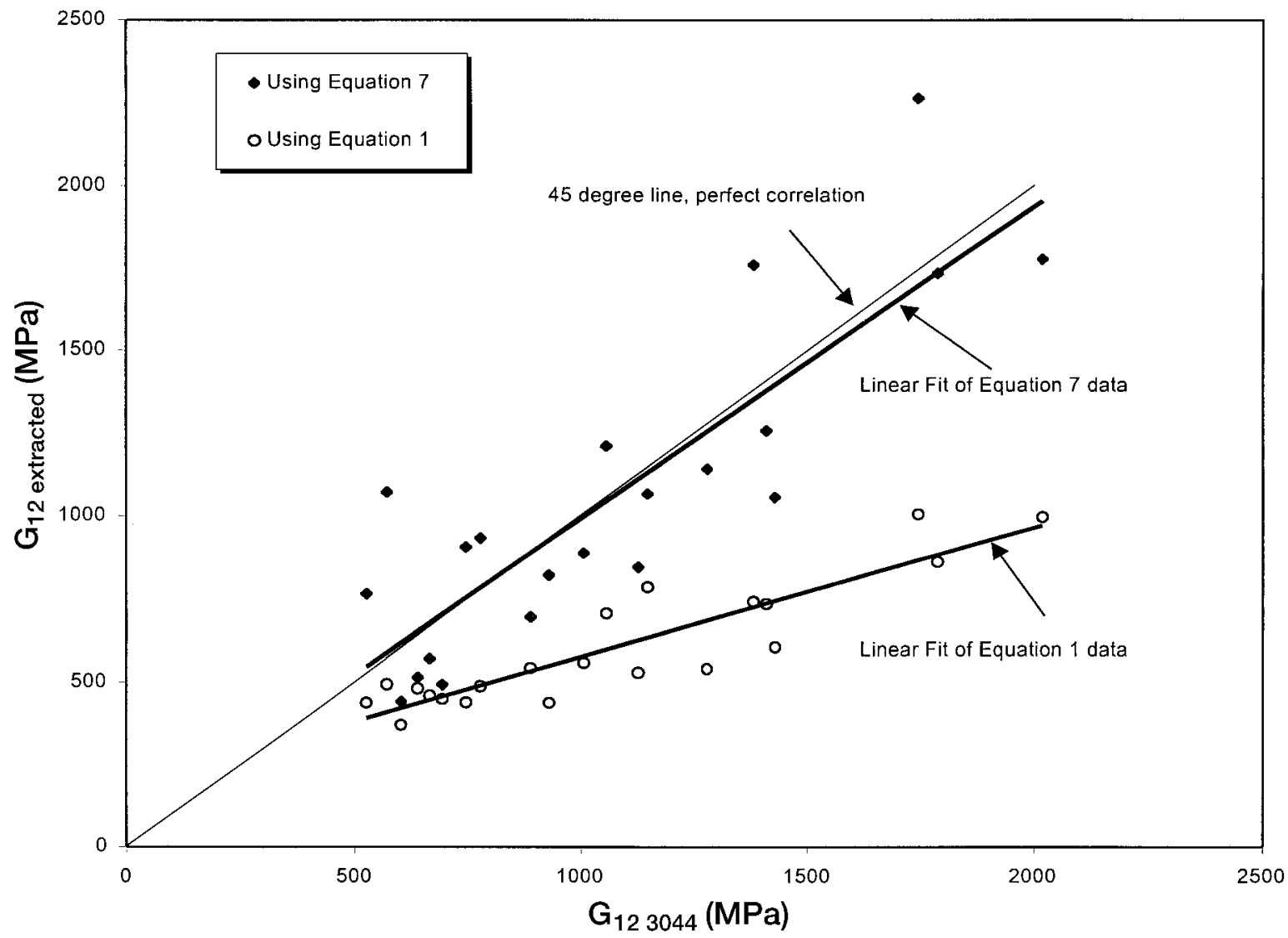

FIG. 3. Comparing $G_{12 \text { extracted }}$ to $G_{123044}$

TABLE 4. Comparison of Shear Modulus Values

\begin{tabular}{|c|c|c|c|c|c|}
\hline $\begin{array}{c}\text { Specimen } \\
\text { (1) }\end{array}$ & $\begin{array}{c}G_{12 \text { eqn } 7} \\
\text { (MPa) } \\
(2)\end{array}$ & $\begin{array}{c}G_{123044} \\
(\mathrm{MPa}) \\
(3)\end{array}$ & $\begin{array}{l}\text { Ratio } \\
G_{12 \text { eqn } 7} / \\
G_{123044} \\
(4)\end{array}$ & $\begin{array}{c}G_{12 \text { eqn } 1} \\
(\mathrm{MPa}) \\
(5)\end{array}$ & $\begin{array}{c}\text { Ratio } \\
G_{12 \text { eqn } 1} / \\
G_{123044} \\
(6)\end{array}$ \\
\hline A1 & 570 & 666 & 0.86 & 481 & 0.72 \\
\hline A2 & 441 & 603 & 0.73 & 381 & 0.63 \\
\hline A3 & 1,071 & 572 & 1.87 & 534 & 0.93 \\
\hline A4 & 763 & 526 & 1.45 & 458 & 0.87 \\
\hline $\mathrm{C} 1$ & 905 & 746 & 1.21 & 451 & 0.60 \\
\hline $\mathrm{C} 2$ & 492 & 693 & 0.71 & 464 & 0.67 \\
\hline N1 & 932 & 777 & 1.20 & 505 & 0.65 \\
\hline N2 & 514 & 640 & 0.80 & 500 & 0.78 \\
\hline $\mathrm{T} 2$ & 1,142 & 1,280 & 0.89 & 555 & 0.43 \\
\hline T3 & 1,056 & 1,429 & 0.74 & 633 & 0.44 \\
\hline $\mathrm{T} 4$ & 886 & 1,005 & 0.88 & 581 & 0.58 \\
\hline T5 & 1,257 & 1,409 & 0.89 & 777 & 0.55 \\
\hline T6 & 1,211 & 1,056 & 1.15 & 739 & 0.70 \\
\hline $\mathrm{T} 7$ & 1,758 & 1,382 & 1.27 & 771 & 0.56 \\
\hline $\mathrm{O} 1$ & 1,732 & 1,788 & 0.97 & 974 & 0.54 \\
\hline $\mathrm{O} 2$ & 2,263 & 1,745 & 1.30 & 1,254 & 0.72 \\
\hline $\mathrm{O} 3$ & 1,776 & 2,018 & 0.88 & 1,209 & 0.60 \\
\hline P1 & 819 & 929 & 0.88 & 567 & 0.61 \\
\hline P2 & 693 & 888 & 0.78 & 703 & 0.79 \\
\hline P3 & 1,067 & 1,147 & 0.93 & 1,017 & 0.89 \\
\hline P4 & 843 & 1,126 & 0.75 & 661 & 0.59 \\
\hline Average & - & - & 1.01 & - & $\phi .66$ \\
\hline $\begin{array}{l}\text { Standard de- } \\
\text { viation }\end{array}$ & - & - & 0.291 & - & $\phi .136$ \\
\hline
\end{tabular}

\section{DISCUSSION OF RESULTS}

The proposed equation [(7)] is generally a better fit than (1) [or the equivalent (3) or (5)]. On some specimens, (1) performed equally as well as (7). A more substantial verification of the new equation is its ability to predict the experimental shear modulus $G_{123044}$ as well as match the $E_{\theta}$ data. Table 4 summarizes these results. The average ratio of $G_{12 \text { eqn } 7} / G_{123044}$
$=1.01$ is excellent, although the standard deviation is quite high at 0.291. Compare this, however, to $G_{12}$ extracted from (1). Here we have better standard deviation (0.123) but the average ratio $G_{12 \text { eqn } 1} / G_{123044}=0.60$. This difference in shear modulus predictions is highlighted in Fig. 3. The scatter of the $G_{12 \text { eqn 1 }}$ data (circles in Fig. 3) is small, but the trendline is nowhere near the target line of $45^{\circ}$. Eq. (7) was calibrated such that the average $G_{12 \text { eqn } 7}$ would be statistically close to $G_{123044}$ (here $G_{12 \text { eqn } 7} / G_{123044}=1.01$ ). This means that individual values of $G_{12}$ predicted by (7) will be higher than $G_{123044}$. It would be possible, however, to redefine (7) to produce a somewhat more conservative value of $G_{12 \text { eqn } 7}$.

This method as presented in this paper requires off-axis data; thus it cannot be used if only parallel and perpendicular to grain test data $\left(E_{1}\right.$ and $\left.E_{2}\right)$ are available. Currently, we are formulating empirical methods of estimating the shear modulus based solely on $E_{1}$ and $E_{2}$.

\section{CONCLUSIONS}

This study has improved the relationship governing the offaxis modulus of elasticity of orthotropic wood-based panels. The newly proposed relationship utilized the modulus of elasticity along the 1 and 2 axes, as well as the shear modulus, and it removed the need for a value of Poisson's ratio. This is an advantage over previous similar studies that required careful measurement of transverse strains. A useful application of the newly proposed equation is to solve it for the shear modulus. This allows for the calculation of shear modulus based solely on axial tests. This could be used to verify in-plane shear modulus data, or it could be used in place of the more cumbersome panel twisting test.

\section{APPENDIX I. REFERENCES}

Annual book of ASTM standards. (1997). Vol. 04.10 Wood, ASTM, West Conshohocken, Pa. 
Bindzi, I., and Samson, M. (1995). "New formula for influence of spiral grain on bending stiffness of wooden beams." J. Struct. Engrg., ASCE, 121(11), 1541-1546.

Bodig, J., and Jayne, B. A. (1982). Mechanics of wood and wood composites. Van Nostrand Reinhold, New York.

Ebrahimi, G., and Sliker, A. (1981). "Measurement of shear modulus by a tension test." Wood Sci., 13(3), 171-176.

"The elastic properties of wood. Young's moduli, moduli of rigidity, and Poisson's ratios of yellow-poplar." (1946). Rep. No. 1528-G, Forest Products Laboratory, Madison, Wisc.

Hearmon, R., and Adams, E. (1952). "The bending and twisting of anisotropic plates." British J. Appl. Phys., 3, 150-156.

Jones, R. M. (1975). Mechanics of composite materials. McGraw-Hill, New York.

Kuipers, J. (1974). "Standard methods of testing for the determination of mechanical properties of plywood." Working commission W18Timber structures, University of Technology, Delft, The Netherlands.

Liu, J. Y., and Ross, R. J. (1998). "Wood mechanical property variation with grain slope." Proc., 12th ASCE Engrg. Mech. Conf., ASCE, Reston, Va., 1351-1354.

Norris, C. B., and McKinnon, P. F. (1956). "Compression, tension and shear tests on yellow-poplar plywood panels of sizes that do not buckle with tests made at various angles to the face grain." Rep. No. 1328, Forest Products Laboratory, Madison, Wisc.
Rosen, B. (1972). "A simple procedure for experimental determination of the longitudinal shear modulus of unidirectional composites." $J$. Compos. Mat., 6, 552-554.

Seo, Y., Castagnede, B., and Mark, R. (1992). “An optimization approach for the determination of in-plane elastic constants of paper.' Tappi J., 11, 209-214.

\section{APPENDIX II. NOTATION}

The following symbols are used in this paper:

$A=$ nondimensional parameter, ratio of $E_{1} / E_{2}$;

$a=$ nondimensional parameter, function of $E_{i}, G$, and $v_{12}$;

$E_{i}=$ Young's modulus or modulus of elasticity, where $i=1$, 2 , or $\theta ; 1$ being strong axis, 2 being weak axis, and $\theta$ being some angle from strong axis;

$G_{\text {eqn } i}=$ shear modulus extracted from off-axis data, $i$ being equation of interest;

$G_{12}=$ shear modulus, along principal axes of panel;

$G_{123044}=$ shear modulus experimentally determined from plate twisting test ASTM D 3044; and

$v_{12}=$ Poisson's ratio. 